\title{
Characterization of three new condensation particle counters for sub-3 nm particle detection during the Helsinki CPC workshop: the ADI versatile water CPC, TSI 3777 nano enhancer and boosted TSI 3010
}

\author{
Juha Kangasluoma $^{1}$, Susanne Hering ${ }^{2}$, David Picard ${ }^{3}$, Gregory Lewis ${ }^{2}$, Joonas Enroth ${ }^{1}$, Frans Korhonen ${ }^{1}$, \\ Markku Kulmala ${ }^{1}$, Karine Sellegri ${ }^{3}$, Michel Attoui ${ }^{1,4}$, and Tuukka Petäjä ${ }^{1}$ \\ ${ }^{1}$ Department of Physics, P.O. Box 64, 00014, University of Helsinki, Helsinki, Finland \\ ${ }^{2}$ Aerosol Dynamics Inc., Berkeley, CA, USA \\ ${ }^{3}$ Laboratoire de Météorologie Physique, UMR6016, Observatoire de Physique du Globe de Clermont-Ferrand, \\ CNRS, Université Blaise Pascal, Clermont-Ferrand, France \\ ${ }^{4}$ University of Paris Est Créteil, University of Paris Diderot, LISA, UMR CNRS 7583, France
}

Correspondence to: Juha Kangasluoma (juha.kangasluoma@helsinki.fi)

Received: 14 December 2016 - Discussion started: 17 January 2017

Revised: 15 May 2017 - Accepted: 16 May 2017 - Published: 19 June 2017

\begin{abstract}
In this study we characterized the performance of three new particle counters able to detect particles smaller than $3 \mathrm{~nm}$ during the Helsinki condensation particle counter (CPC) workshop in summer 2016: the Aerosol Dynamics Inc. (ADI; Berkeley, USA) versatile water condensation particle counter (vWCPC), TSI 3777 nano enhancer (TSI Inc., Shoreview, USA) and modified and boosted TSI 3010-type CPC from Université Blaise Pascal called a B3010. The performance of all CPCs was first measured with charged tungsten oxide test particles at temperature settings which resulted in supersaturation low enough to not detect any ions produced by a radioactive source. Due to similar measured detection efficiencies, additional comparison between the 3777 and vWCPC were conducted using electrically neutral tungsten oxide test particles and with positively charged tetradodecylammonium bromide. Furthermore, the detection efficiencies of the 3777 and vWCPC were measured with boosted temperature settings yielding supersaturation which was at the onset of homogeneous nucleation for the 3777 or confined within the range of liquid water for the ADI vWCPC. Finally, CPC-specific tests were conducted to probe the response of the 3777 to various inlet flow relative humidities, of the B3010 to various inlet flow rates and of the vWCPC to various particle concentrations. For the 3777 and vWCPC the measured $50 \%$ detection diameters (d50s) were
\end{abstract}

in the range of $1.3-2.4 \mathrm{~nm}$ for the tungsten oxide particles, depending on the particle charging state and CPC temperature settings, between 2.5 and $3.3 \mathrm{~nm}$ for the organic test aerosol, and in the range of $3.2-3.4 \mathrm{~nm}$ for tungsten oxide for the B3010.

\section{Introduction}

The work of Stolzenburg and McMurry (1991) started a new chapter in aerosol research with their prototype laminar flow condensation particle counter (CPC) capable of detecting $3 \mathrm{~nm}$ aerosol particles via condensation of butanol vapor. Compared to the previous CPC designs, the significant improvements in the instrument included minimized diffusion losses in the sampling line and a sheath flow in the condenser to focus the particle beam to the maximum butanol supersaturation region in the middle of the condenser (Wilson et al., 1983). This instrument is the predecessor of the ultrafine CPC 3025A and 3776 (TSI Inc., Shoreview, USA), which are currently widely used in various fields of aerosol science to study particle dynamics at particle sizes larger than $3 \mathrm{~nm}$ (e.g. Weber et al., 1996; Aalto et al., 2001).

It was not possible to detect particles smaller than $3 \mathrm{~nm}$ with the CPC technology until 1997, when Seto et al. (1997) 


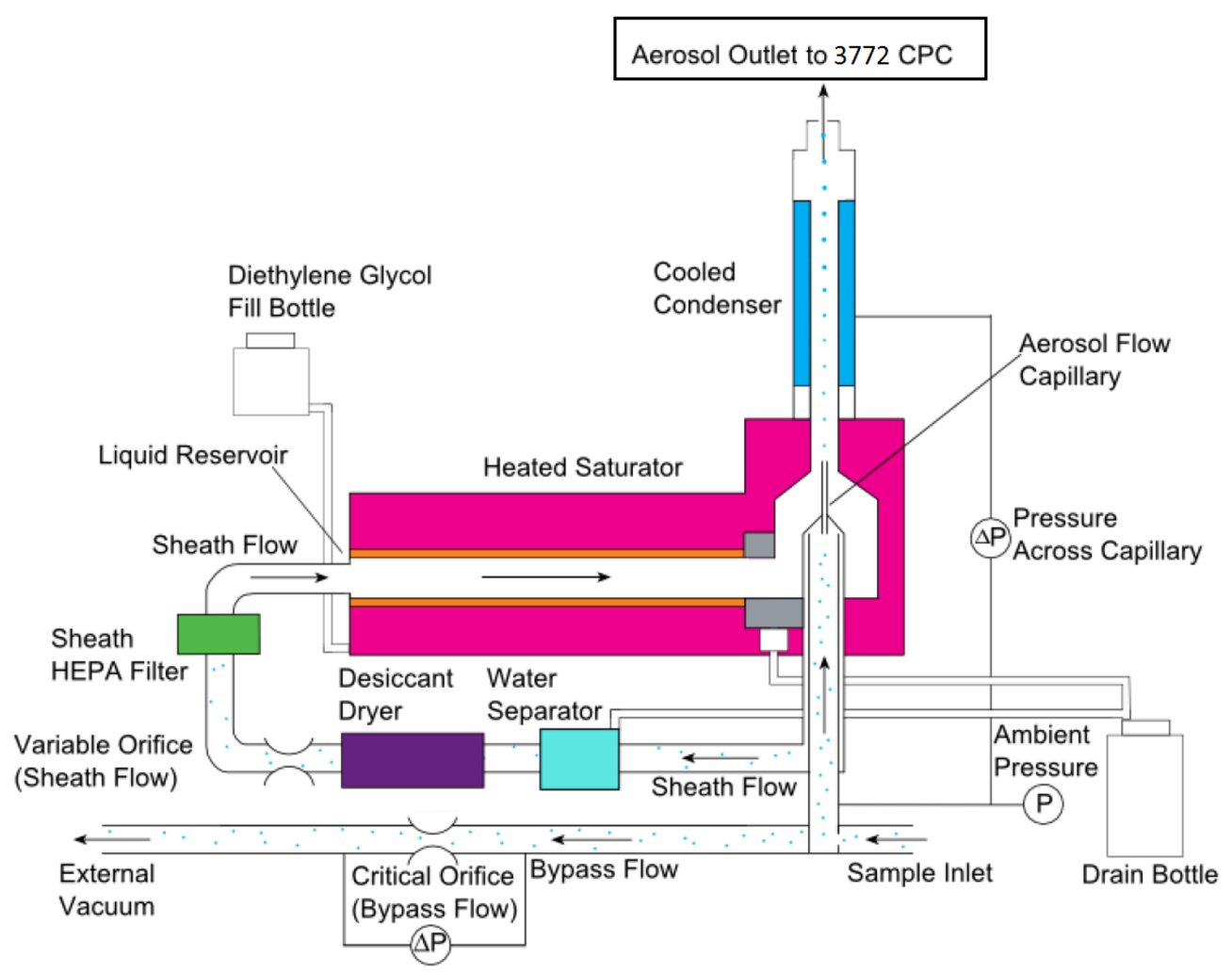

Figure 1. TSI 3777 nano enhancer (courtesy of TSI Inc.).

published their design on the particle size magnifier (PSM) used to study heterogeneous nucleation of dibutyl phthalate vapor onto small ions. Their advances were made possible by the development of a new differential mobility analyzer (DMA) combined to an electrospray source, allowing the CPC testing with well-characterized monomobile samples. Their CPC was based on the design of Okuyama et al. (1984), which is a mixing-type CPC. It took until 2011 to commercialize the diethylene glycol (DEG)-based mixing-type CPC technology, when Vanhanen et al. (2011) published their version of the DEG-based PSM, today sold as the Airmodus A10 PSM (A11 nano condensation nuclei counter when combined to Airmodus A20 butanol CPC).

The first use of DEG as a CPC working fluid was reported by Iida et al. (2009), who studied sub-3 $\mathrm{nm}$ particle detection via heterogeneous nucleation with many different working fluids theoretically and experimentally. They modified the TSI 3025A to operate with DEG and showed particle activation and growth starting from $1 \mathrm{~nm}$ in mobility diameter. Because the grown DEG droplets are too small for direct optical detection, a traditional butanol-based CPC was used as the droplet detector. The idea of modifying the commercial TSI instrument to operate with DEG has been followed by several other researchers (Jiang et al., 2011a, b; Kuang et al., 2012a, b; Wimmer et al., 2013). In 2016 TSI commercialized the DEG-based laminar-type CPC based on the work of Iida et al. (2009). This instrument, the TSI 3777 nano enhancer (3777), is one of the three instruments characterized in this study (Fig. 1).

Generally, laminar flow ultrafine CPCs use a sheathed condenser, which makes the CPC design more complex compared to non-sheathed CPCs. Yet recent efforts have shown comparably low detection limits with unsheathed laminar flow instruments. Particle detection with the butanol-based TSI 3010 has been shown down to $2.5 \mathrm{~nm}$ from the factory settings d50 (diameter at which $50 \%$ of sampled particles are detected) of $10 \mathrm{~nm}$ (Mertes et al., 1995; Russell et al., 1996; Wiedensohler et al., 1997). Kangasluoma et al. (2015a) showed $1 \mathrm{~nm}$ particle detection with the commercial unsheathed laminar-type CPCs TSI 3772 and Airmodus A20 by increasing the temperature difference (dT) between the saturator and condenser up to $40^{\circ} \mathrm{C}$. The second CPC characterized in this study is a boosted TSI 3010 (B3010), which is a modification of the commercial TSI 3010 developed at the Université Blaise Pascal (Fig. 2). In this instrument the temperature control of the saturator and condenser is decoupled to allow free selection of the temperatures, and the critical orifice is replaced with a flow meter and a miniature rotary vane pump.

The disadvantage of all the previous CPCs is the slight toxicity of the working fluids butanol and DEG, and these organic liquids can introduce contaminant molecules to va- 


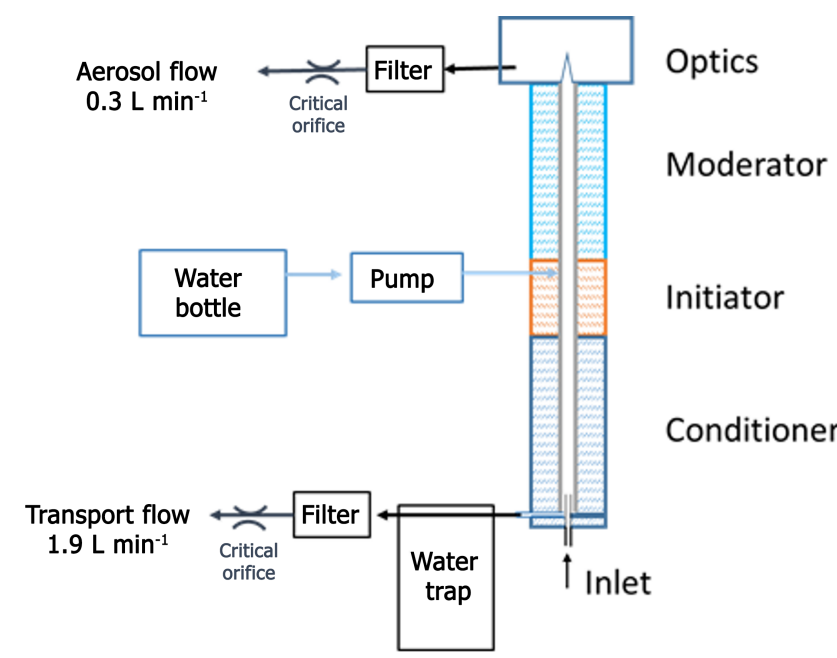

Figure 2. ADI vWCPC.

por phase. Hering et al. (2005) addressed this issue by developing a water-based, laminar flow technology (Hering and Stolzenburg, 2005), which was commercialized as the TSI WCPC models 3785 (Hering et al., 2005) and 3786 (Iida et al., 2008) and subsequently as the models 3783,3787 and 3788. In the model 3786, and later in the model 3788 (Kupc et al., 2013), $3 \mathrm{~nm}$ particle detection was enabled by introducing a similar sheathed condenser as in the butanol-based CPCs.

The Aerosol Dynamics Inc. (ADI) versatile water CPC (vWCPC), which is the third CPC characterized in this study (Fig. 3), advances the laminar flow water-based CPC through a three-stage design that reduces the water vapor saturation and temperature in the growth tube after the peak supersaturation is achieved and yet allows for continued particle growth (Hering et al., 2016). This three-stage approach facilitates higher temperature differences between the first two stages and can produce higher peak supersaturation values than the ultrafine TSI 3786 or TSI 3788 . The vWCPC is an unsheathed instrument operating at an aerosol flow rate of $0.3 \mathrm{~L} \mathrm{~min}^{-1}$ and at more extreme temperatures than all of the current commercial TSI WCPCs. In contrast to the DEGbased instruments, which require a separate $\mathrm{CPC}$ as a detector due to the small size of the DEG droplets, the droplets formed in the growth tube of the vWCPC are sufficiently large for direct optical detection.

The aim of this study is to make intercomparison experiments for the three new particle counters. Each of the CPCs are operated with different working fluids utilizing different geometries, and first we find the d50 for tungsten oxide test particles for each CPC at temperature settings where do not detect ions from a radioactive source. As the 3777 and vWCPC exhibited very similar performance in terms of d50, we conduct a further comparison to the two CPCs by testing their response at a higher supersaturation than the factory set- tings, to electrically neutral particles, to organic test particles and to urban ambient particles. Furthermore, we conducted CPC-specific experiments to probe the response of 3777 to varying sample flow relative humidity, of B3010 with various inlet flow rates and of vWCPC to sampled particle concentration.

\section{Experimental}

\subsection{Condensation particle counters}

A flow diagram of the 3777 is presented in Fig. 1. The design is largely similar to the TSI ultrafine 3776 . The inlet flow rate (Qinlet) is $2.5 \mathrm{~L} \mathrm{~min}^{-1}$, with $1.5 \mathrm{~L} \mathrm{~min}^{-1}$ of that being transport flow and $1 \mathrm{~L} \mathrm{~min}^{-1}$ split as the sheath flow $\left(0.85 \mathrm{~L} \mathrm{~min}^{-1}\right)$ and aerosol flow (Qaerosol, $\left.0.15 \mathrm{~L} \mathrm{~min}^{-1}\right)$. The sheath flow passes through a desiccant drier to remove most water vapor entering the condenser. Downstream of the drier the sheath flow is saturated with DEG before entering the condenser around the aerosol flow, which is guided in the center line of the condenser. The saturator has a meandering path in a metal block instead of a porous wick used in ultrafine butanol-based CPCs. The 3777 does not have its own optics head, as the droplets formed by DEG condensation are too small for direct detection. Instead the detector is a TSI 3772 CPC, which further enlarges and then counts the droplets pre-grown by DEG in the condenser. The factory settings of the 3777 are as follows: the saturator at $62^{\circ} \mathrm{C}$ and condenser at $12{ }^{\circ} \mathrm{C}$ (low temperature difference settings). At these settings the 3777 did not detect any ions produced by an aerosol neutralizer whose bipolar ion source is a $185 \mathrm{MBq}$ radioactive ${ }^{241} \mathrm{Am}$ source. It was also operated at boosted settings so that the supersaturation was at the onset of homogeneous nucleation. With the boosted settings the saturator temperature was set to $70^{\circ} \mathrm{C}$ and condenser to $7^{\circ} \mathrm{C}$ (high dT settings).

Flow diagram of the ADI vWCPC is presented in Fig. 2. The vWCPC does not require a separate CPC for droplet detection, nor does it use a sheath flow, making it a relatively simple CPC. The vWCPC has two flows, a transport flow and an aerosol flow, both of which are controlled by critical orifices. For experiments conducted here the inlet flow rate of the $\mathrm{vWCPC}$ was $2.2 \mathrm{~L} \mathrm{~min}^{-1}$, of which $1.9 \mathrm{~L} \mathrm{~min}^{-1}$ is transport flow and $0.3 \mathrm{~L} \mathrm{~min}^{-1}$ aerosol flow. The aerosol flow passes upward through a three-stage growth tube consisting of a cool-walled conditioner, followed by a short, warm-walled initiator, and subsequently followed by a coolwalled moderator (Hering et al., 2014). A continuous wick spans all three growth tube sections. Liquid water is injected at a rate of $1 \mu \mathrm{L} \mathrm{min}^{-1}$ at the initiator, and excess drains toward the inlet and is removed with the transport flow. Peak supersaturation and particle activation occurs within the initiator, and growth continues in the moderator. The formed droplets are counted by an optics head mounted directly at 


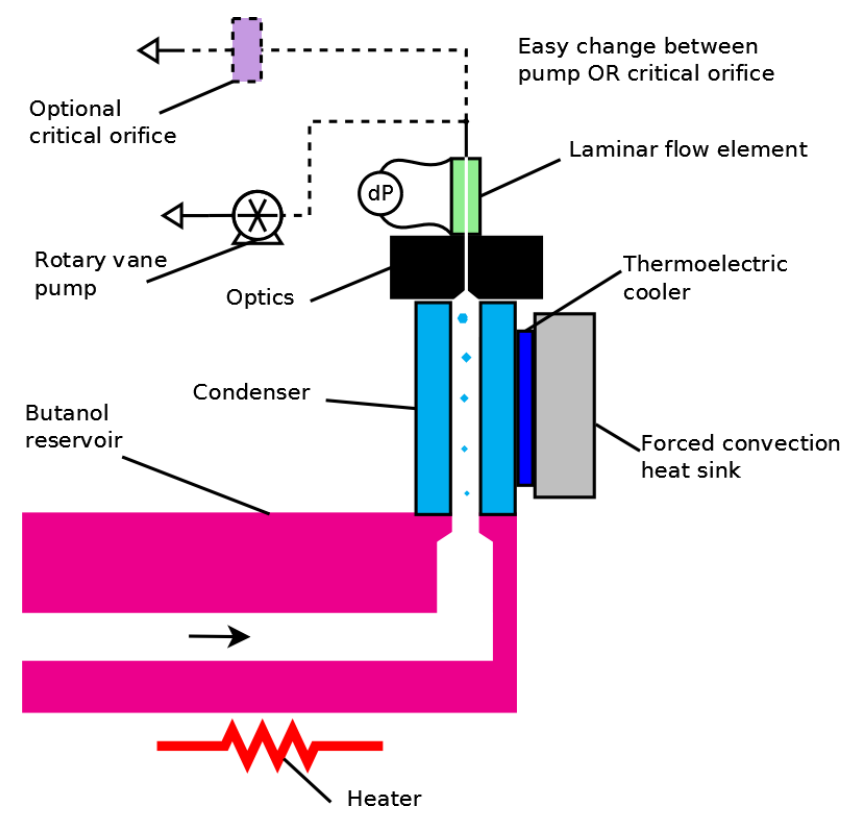

Figure 3. B3010.

the outlet of the growth tube. Further detail is presented by Hering et al. (2016). The vWCPC was tested at two different temperature settings: the conditioner at $8^{\circ} \mathrm{C}$ and initiator at $90^{\circ} \mathrm{C}$ (low dT settings), corresponding to supersaturation low enough to not detect any ions from the $185 \mathrm{MBq}$ radioactive ${ }^{241} \mathrm{Am}$ source, and boosted settings with the conditioner at $1{ }^{\circ} \mathrm{C}$ and initiator at $95^{\circ} \mathrm{C}$ (high dT settings), which is close to the extremes attainable without freezing or boiling. In both instances the moderator was operated at $22^{\circ} \mathrm{C}$ and the optics head at $40^{\circ} \mathrm{C}$. At the high dT settings both 3777 and vWCPC are able to detect ions from the ${ }^{241} \mathrm{Am}$ source.

The B3010 is based on the robust TSI 3010 (Fig. 3), from which everything except the saturator block, the condenser and the optical detector are removed. The original electronics have been replaced with custom-made boards to handle the higher power consumption and operate off 28 VDC, the primary power supply in aircrafts. The whole system is controlled by a credit-card-sized ARM computer running a tailor-made embedded Linux operating system. It features a touchscreen, a TSI-like serial port protocol, and digital pulse output. With these modifications the saturator heating and condenser cooling are decoupled. In addition, the critical orifice and external heavy pump are replaced by a laminar flowmeter and a miniature rotary vane pump. The user may set the temperature of the saturator, condenser and optics as well as the flow rate independently from one another. The B3010 was operated at saturator temperature $55^{\circ} \mathrm{C}$, optics head $56^{\circ} \mathrm{C}$ and condenser $11^{\circ} \mathrm{C}$. The B3010 will be described in more detail in a dedicated article, which is presently in preparation. Table 1 summarizes the instrument operation conditions.

\subsection{Direct comparison of all CPCs}

Two methods were used to generate the test aerosol: glowing wire generator (GWG) and electrospray source. In the GWG (Peineke et al., 2006), a thin, $0.4 \mathrm{~mm}$ in diameter, tungsten wire is heated resistively in a metal chamber. The wire is flushed with $5.0 \mathrm{~N}_{2}$ flow, and it has been shown that negatively charged tungsten oxide clusters are formed into the $\mathrm{N}_{2}$ flow without additional charging (Kangasluoma et al., 2015b). Positively charged clusters contain some hydrocarbon molecules clustered with tungsten oxide, explaining why the measured $\mathrm{d} 50$ is usually larger for positively than negatively charged clusters (Kangasluoma et al., 2016b). Eighteen different sizes of particles between 1 and $4.5 \mathrm{~nm}$ were selected with the Herrmann-type high-resolution DMA (Kangasluoma et al., 2016a; Fig. 4) and guided to a test CPC and TSI aerosol electrometer (3068B). The tubing lengths downstream of the DMA were selected based on the inlet flow rates so that the particle penetration through the tubes can be assumed equal. The $\mathrm{d} 50$ for all three CPCs at low dT settings was measured with tungsten oxide particles.

\subsection{Comparison between the 3777 and the vWCPC}

The dT of the 3777 and the vWCPC was increased to the extent possible, and the d50 was measured similarly as described in Sect. 2.2 for tungsten oxide particles. The maximum dT of the 3777 is limited by the onset of homogeneous nucleation, while the maximum dT for the vWCPC is restricted by the freezing and boiling points of water.

To measure the d50 for neutral particles, we followed the approach presented in our previous studies (Kangasluoma et al., 2015b, 2016b). The sample flow downstream of the DMA passes through a mixing chamber, to which a tube containing a ${ }^{241} \mathrm{Am}$ radioactive source is connected. A total of $0.2 \mathrm{~L} \mathrm{~min}^{-1}$ of the sample flow is drawn through the tube, and ions from the radioactive source are drifted to the mixing chamber against the counter flow with an electric field. A fraction of the sample particles are neutralized by the opposite polarity ions drifted to the mixing chamber. An ion precipitator is placed downstream of the mixing chamber to allow sampling of only neutral particles with the CPC. The concentration detected with the CPC is normalized against the electrometer. The detection efficiency curve is further normalized with detection efficiency at the largest selected diameters where the role of charge on the detection efficiency is assumed to be negligible. This method yields uncertainties in the resulting d50 due to possibly size-dependent neutralization efficiency, unknown neutralization mechanism (ionion recombination leading to larger physical size, or charge transfer) and chemical composition of the neutralized particles; however, it is currently the only method to measure d50 for neutral particles for sub-3 nm particles. Winkler et al. (2008) used a similar method to measure nucleation probabilities of electrically charged and neutral clusters, with the 
Table 1. Instrument operation conditions.

\begin{tabular}{lrrlrrrr}
\hline Instrument & $\begin{array}{r}\text { Qinlet } \\
\left(\mathrm{L} \mathrm{min}^{-1}\right)\end{array}$ & $\begin{array}{r}\text { Qaerosol } \\
\left(\mathrm{L} \mathrm{min}^{-1}\right)\end{array}$ & Settings & $\begin{array}{r}\mathrm{Ts} \\
\left({ }^{\circ} \mathrm{C}\right)\end{array}$ & $\begin{array}{r}\mathrm{Tc} \\
\left({ }^{\circ} \mathrm{C}\right)\end{array}$ & $\begin{array}{r}\mathrm{Tm} \\
\left({ }^{\circ} \mathrm{C}\right)\end{array}$ & $\begin{array}{r}\text { To } \\
\left({ }^{\circ} \mathrm{C}\right)\end{array}$ \\
\hline B3010 & 1 & 1 & Low dT & 55 & 10 & & 56 \\
vWCPC & 2.2 & 0.3 & Low dT & 8 & 90 & 22 & 40 \\
vWCPC & 2.2 & 0.3 & High dT & 1 & 95 & 22 & 40 \\
3777 & 2.5 & 0.15 & Low dT & 62 & 12 & & \\
3777 & 2.5 & 0.15 & High dT & 70 & 7 & & \\
\hline
\end{tabular}

difference being that they used bipolar neutralizer. Neutral d50 was measured for both instruments with high and low dT by neutralizing both negatively and positively charged particles.

To test the response of the 3777 and the $\mathrm{vWCPC}$ to organic test particles, tetradodecylammonium bromide (TDDABr; Ude and Fernández de la Mora, 2005) particles were generated with an electrospray source. The electrospray source produces droplets, which contain the sample molecules, by spraying liquid at high voltage out of a capillary needle against a grounded electrode. The charged droplets are close to the Rayleigh limit and produce charged sample molecules and clusters to the gas flow by series of Coulomb explosions and ion and solvent evaporation from the droplet. The highly charged droplets can be close to $2 \mathrm{~nm}$ in mobility diameter (Ude and Fernández de la Mora, 2005), for which we neutralized the flow exiting the electrospray with a radioactive ${ }^{241} \mathrm{Am}$ source to also be able to sample the singly charged clusters which are larger than $2 \mathrm{~nm}$ (Kangasluoma et al., 2016a). d50 was measured for the 3777 and vWCPC for positively charged TDDABr with the low dT settings and for the vWCPC at the high dT settings. For the 3777 we could not measure the $\mathrm{d} 50$ at high dT settings due to the fact that the aerosol-to-sheath flow ratio is very sensitive to the CPC inlet pressure, and TDDABr was produced by drawing the flow out of the DMA, leading to a pressure drop of approximately $5 \mathrm{kPa}$ at the CPC inlets. This pressure drop was enough to alter the aerosol-to-sheath flow ratio in the 3777 and cause homogeneous droplet formation at high dT settings.

Finally, the 3777 and vWCPC were placed to sample atmospheric aerosol from the Helsinki city area. The instruments were sampling from the same inlet for approximately $18 \mathrm{~h}$ to compare the measured concentrations from atmospheric aerosol. The vWCPC data were dead time corrected using the dead time correction factor derived from the concentration-dependent response for $4.4 \mathrm{~nm}$ (see next section).

\subsection{CPC-specific tests}

As previous literature has reported that water vapor in the sample flow can affect the detection efficiency of a DEGbased CPC (Iida et al., 2009; Kangasluoma et al., 2013), we measured the d50 of the 3777 at various sample flow dew

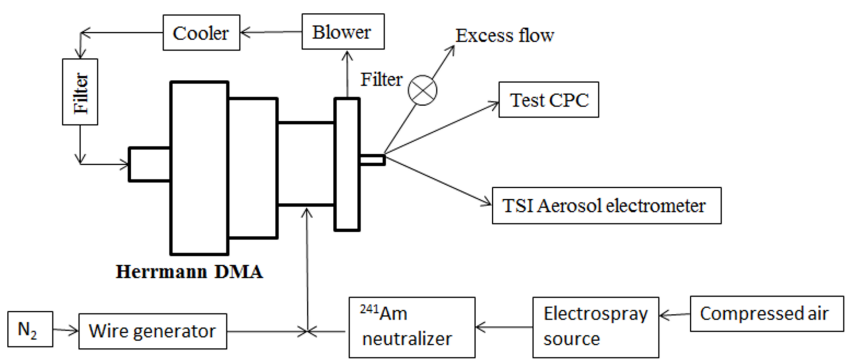

Figure 4. Experimental setup to measure d50 for charged particles.

points. Water vapor was added to the sample flow with a humidified dilution flow downstream of the DMA. The d50 of the 3777 was measured at four different sample flow dew points with negatively charged tungsten oxide particles.

Based on previous literature (Kangasluoma et al., 2015a), the detection efficiency of the laminar-type butanol CPCs can be increased by increasing the inlet flow rate. We tested the performance of the B3010 at four different inlet flow rates. The $\mathrm{d} 50$ for the $\mathrm{B} 3010$ was measured at inlet flow rates, 0.5 , $1.0,1.4$ and $1.6 \mathrm{~L} \mathrm{~min}^{-1}$, by varying the rotary vane pump speed.

Water-based CPCs are known to be sensitive for vapor depletion effects (Lewis and Hering, 2013). Therefore, the response of the vWCPC was measured against the TSI electrometer (model 3068B) for different concentrations at sizes $1.4,1.8,2.4$ and $4.4 \mathrm{~nm}$. The concentration at each size was controlled by adding a dilution flow of compressed and filtered air downstream of the DMA. Simultaneous data were collected for the 3777; however, the dilution flow was again enough to change the aerosol-to-sheath flow ratio of the 3777 due to a small change in the inlet pressure, and therefore the 3777 data of this experiment are not presented. However, assuming that any possible undercounting at high concentration originates from particle coincidence in the optics, the concentration calibration of the 3777 should be practically the same as of the 3772 CPC when the dilution of $0.15 / 1$ is taken into account. 
Table 2. All measured d50s (nm).

\begin{tabular}{lllrrr}
\hline Conditions & Aerosol & Charging state & ADI vWCPC & TSI-3777 & B3010 \\
\hline High dT & WOx & negative & 1.4 & 1.3 & NA \\
High dT & WOx & positive & 1.5 & 1.4 & NA \\
High dT & WOx & neutral from - & 1.6 & 1.5 & NA \\
High dT & WOx & neutral from + & 2.2 & 2.1 & NA \\
Low dT & WOx & negative & 1.7 & 1.8 & 3.4 \\
Low dT & WOx & positive & 1.9 & 2 & 3.2 \\
Low dT & WOx & neutral from - & 2 & 1.9 & NA \\
Low dT & WOx & neutral from + & 2.4 & 2.3 & NA \\
High dT & TDDAB & positive & 2.8 & NA & NA \\
Low dT & TDDAB & positive & 3.3 & 2.5 & NA \\
\hline
\end{tabular}

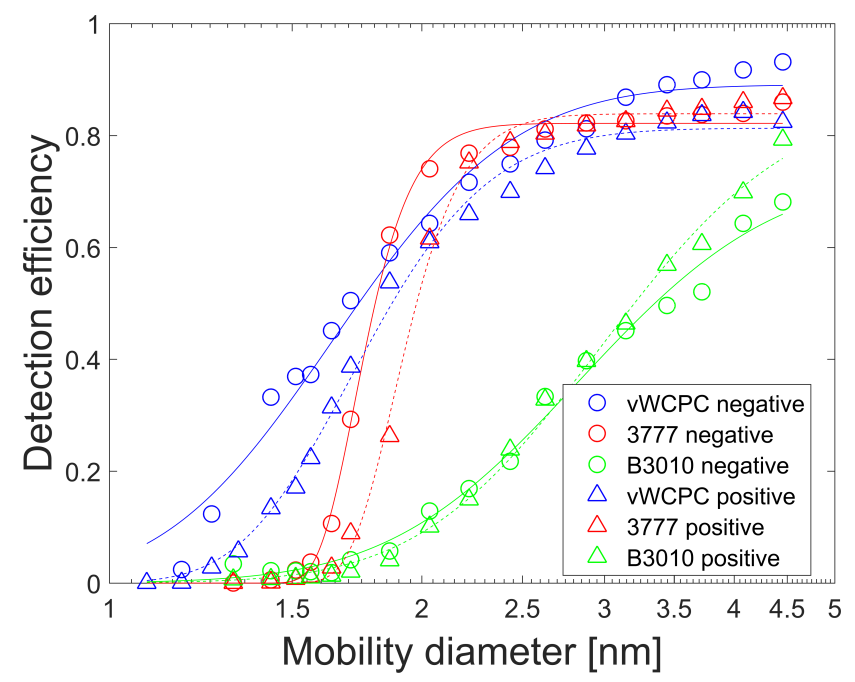

Figure 5. Detection efficiency of the CPCs as a function of size for negatively and positively charged tungsten oxide particles at low dT settings.

\section{Results}

\subsection{Direct comparison of all CPCs}

Figure 5 presents the $\mathrm{d} 50$ curves for the B3010, 3777 and vWCPC at low dT settings for positively and negatively charged tungsten oxide particles. The standard deviation in the detection efficiency data was in most cases $<5 \%$, which is why we do not plot detection efficiency error bars. The $x$ axis uncertainty can be taken from the Herrmann DMA resolution of approximately 20 , leading to relative uncertainty of $\pm 2 \%$, which is the square root of variance of the normal distribution fitted to the tetraheptylammonium bromide positively charged monomer peak. Therefore, uncertainties in the data arise mostly from other sources, such as possibly unequal sampling line penetration or possibly changing particle chemical composition as a function of size. At these settings none of the CPCs detect the ions generated by a bipolar ion source. We find that the vWCPC exhibits slightly lower d50 than the 3777 , while the $\mathrm{d} 50$ of the $\mathrm{B} 3010$ is clearly the highest. The d50 of 3.2-3.4 nm for the B3010, however, shows that the conventional TSI 3010 can be boosted to similar performance as the TSI ultrafine 3776, just with a shallower d50 curve due to larger particle diffusion losses, by decoupling the heating and cooling of the saturator and condenser. Respective d50 values for the B3010, vWCPC and TSI-3777 are 3.4, 1.7 and $1.8 \mathrm{~nm}$, for negatively charged tungsten oxide, and 3.2, 1.9 and $2.0 \mathrm{~nm}$, for positively charged ones.

\subsection{Comparison between the 3777 and the vWCPC}

At high dT settings the d50 curves are presented in Fig. 6. For the 3777 the temperatures were selected as those that are just below the limit of homogeneous nucleation of the DEG working fluid. For the vWCPC, the temperatures are simply the largest extremes attainable without freezing or boiling the water working fluid. Unlike the DEG instrument, the high dT operation of the vWCPC is not near the homogeneous nucleation limit, as no evidence of homogeneous nucleation was observed even at reduced inlet pressures. At these higher dT settings, we find somewhat more efficient detection of smaller particles by the 3777 than the vWCPC. The d50s are lowered to 1.4 and $1.3 \mathrm{~nm}$ for negatively charged and to 1.5 and $1.4 \mathrm{~nm}$ for positively charged for the vWCPC and 3777 , respectively.

Table 2 summarizes the measured d50 for all experiments. The d50 for 3777 and vWCPC at both settings is lower for negatively charged particles than for positively charged particles. This is observed throughout the past literature (Stolzenburg and McMurry, 1991; Winkler et al., 2008; Sipilä et al., 2009; Kuang et al., 2012b; Kangasluoma et al., 2014) and explained by hydrocarbon contaminants in the positively charged particles (Kangasluoma et al., 2016b). Based on previous literature (Kuang et al., 2012b; Kangasluoma et al., 2014) slightly lower $d 50$ values can be expected for inorganic salt particles than the measured d50s for tungsten oxide particles in this study. TSI states in their instrument brochure a d50 of $1.4 \mathrm{~nm}$ for negatively charged $\mathrm{NaCl}$ particles at factory settings (low dT in this study), which is well in line 


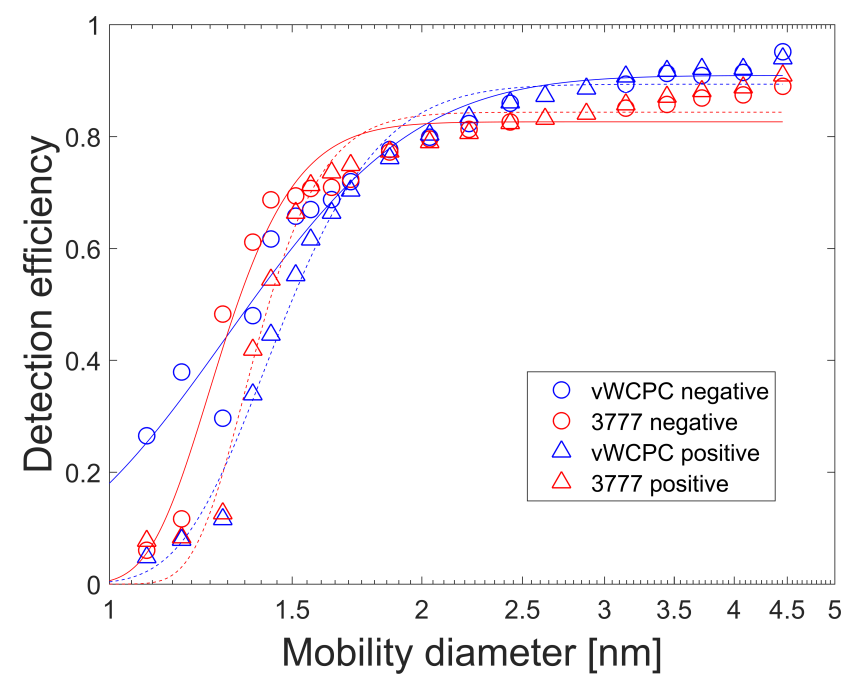

Figure 6. Detection efficiency of the CPCs as a function of size for positively and negatively charged tungsten oxide particles at high dT settings.

with this study. Similarly, the d50 values reported here for the vWCPC are close to those observed by Hering et al. (2016), who measured d50 of 1.6 and $1.9 \mathrm{~nm}$ for high dT and low dT operation, respectively, for particles from a heated $\mathrm{NiCr}$ wire.

Figure 7 presents the d50 curves measured with the neutralized tungsten oxide particles for 3777 and vWCPC. The data is normalized so that the mean detection efficiency at three largest diameters is $90 \%$ based on the assumption that at those sizes the particle charge does not affect the detection efficiency anymore. It is also assumed through the normalization that the neutralization efficiency does not change as a function of the particle size. Further uncertainties arise from the unknown processes that take place during neutralization. Due to these uncertainties, the curves are not as smooth as for the charged particles. However, an estimate for the neutral $\mathrm{d} 50$ will be obtained from these experiments, which are 1.6 and $1.5 \mathrm{~nm}$ for vWCPC and 3777 at high dT and 2.0 and $1.9 \mathrm{~nm}$ at low dT settings, respectively, for neutralized negatively charged tungsten oxide. For neutralized positively charged particles the respective values are 2.2 and $2.1 \mathrm{~nm}$ at high dT settings and 2.4 and $2.3 \mathrm{~nm}$ at low dT settings (Fig. 8). The difference in the d50s between the negatively and positively charged particles after neutralization are possibly mostly explained by their differences in the chemical composition. Positively charged particles contain more contaminant species than the negatively charged particles, which is still observed in the d50 when they both are neutralized. For more details, refer to Kangasluoma et al. (2016b). The neutral $\mathrm{d} 50 \mathrm{~s}$ are greater than for charged d50 values by approximately $0.1-0.5 \mathrm{~nm}$ at low dT settings, similar to the values obtained in Kangasluoma et al. (2016b) for water tungsten oxide and DEG tungsten oxide system.

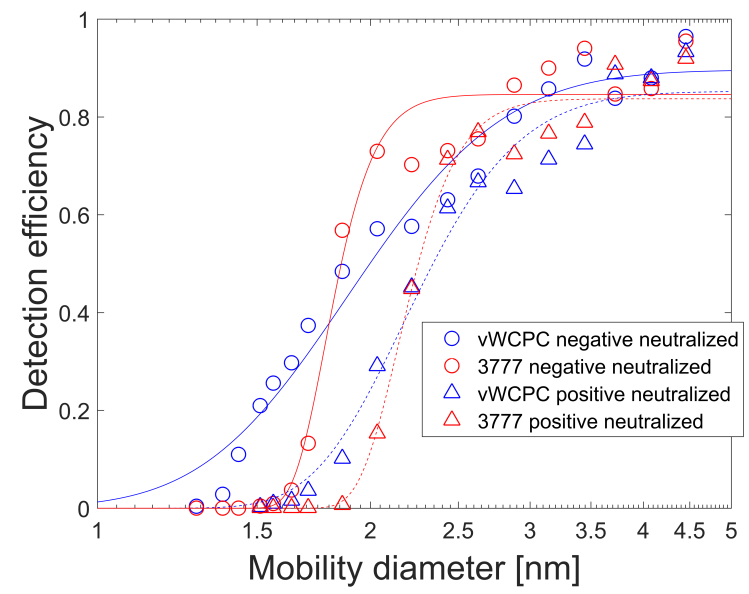

Figure 7. Detection efficiency of the CPCs as a function of size for negatively and positively charged tungsten oxide particles that are neutralized at low dT settings.

The d50 curves for positively charged TDDABr for the 3777 and vWCPC are presented in Fig. 9. For both instruments the $\mathrm{d} 50$ values are higher than for tungsten oxide particles, but this is most pronounced for the vWCPC. At the low dT settings d50 values are 3.3 and $2.5 \mathrm{~nm}$ for the vWCPC and 3777 , respectively, and $2.8 \mathrm{~nm}$ for the vWCPC at high dT. At the high $\mathrm{dT}$ and the reduced inlet pressure for these TDDABr tests, the 3777 produced homogeneously nucleated particles, and hence its high dT d50 value could not be measured. To obtain accurate particle concentration measurements, these differences in the d50 imply that the CPCs should be calibrated with the same aerosol composition as the real experiment is conducted.

A fraction of the data measured from atmospheric aerosol is presented in Fig. 10. The measurement location is above a bus stop, through which several busses pass daily. The bus stop times are marked in the figure. The background aerosol concentration during that morning was around 3000 $10000 \mathrm{~cm}^{-3}$. Clear spikes up to $200000 \mathrm{~cm}^{-3}$ in the measured concentrations are observed throughout the morning. The number concentration is generally high during traffic hours, and both CPCs reacts instantaneously to the occasional spikes in the number concentration. From the data of Fig. 10, a correlation plot between the vWCPC and 3777 is presented in Fig. 11 for concentrations below $50000 \mathrm{~cm}^{-3}$. With an $R^{2}$ of 0.99 the two CPCs show remarkably good agreement with a slope of 1.02 and an offset of 340 up to concentrations of $50000 \mathrm{~cm}^{-3}$.

\subsection{CPC-specific tests}

Because water vapor has been observed to alter the d50 in the original laminar flow DEG instruments, this question was examined for the 3777 . The response of the 3777 for negatively charged tungsten oxide particles as a function of sample flow 


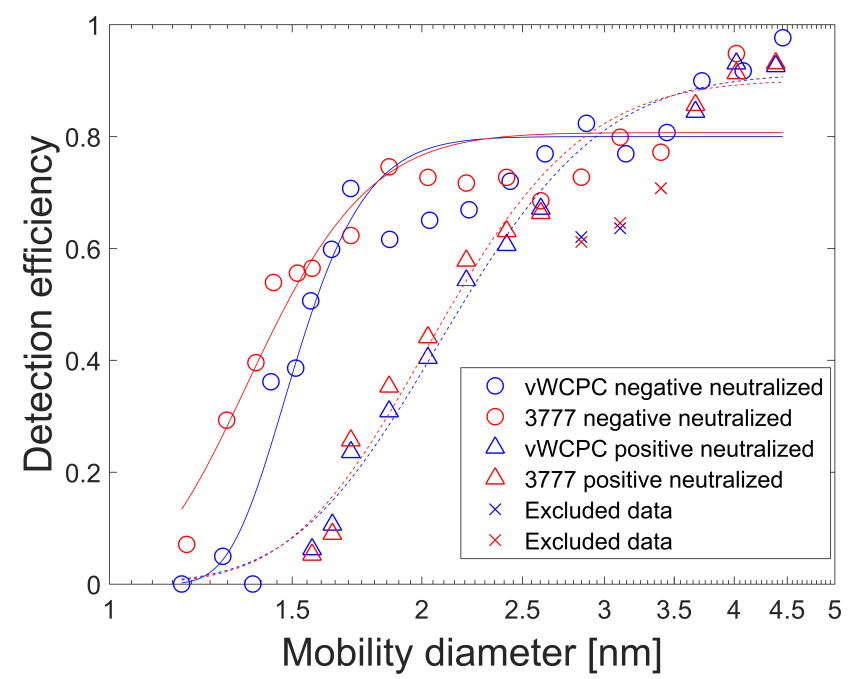

Figure 8. Detection efficiency of the CPCs as a function of size for negatively and positively charged tungsten oxide particles that are neutralized at high dT settings.

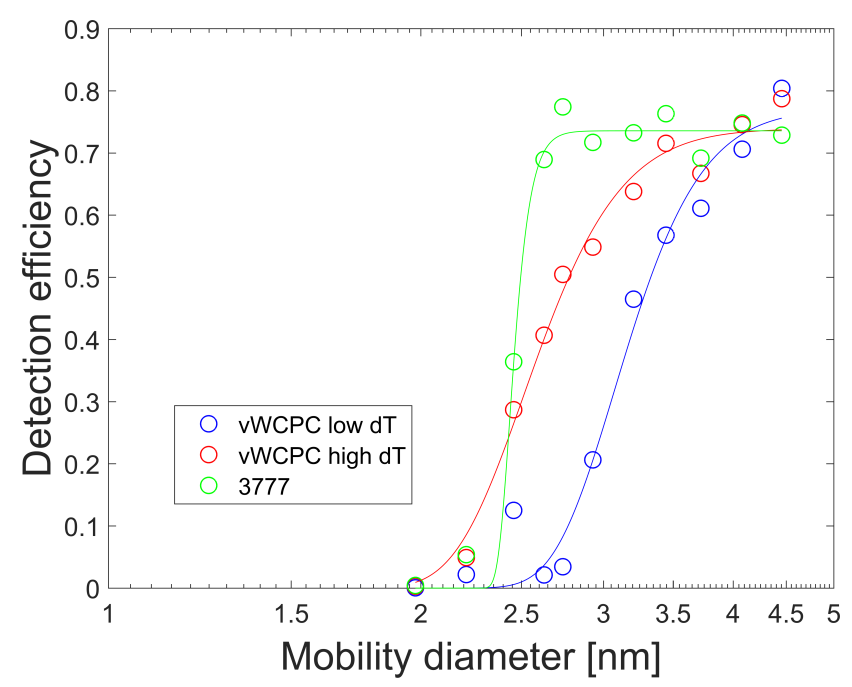

Figure 9. Detection efficiency of the CPCs as a function of size for positively charged TDDABr particles at low and high dT settings for vWCPC and at low dT settings for the 3777 .

dew point is presented in Fig. 12. The observed variation with dew points ranging from completely dry gas to $20^{\circ} \mathrm{C}$ in the d50 is only approximately $0.1 \mathrm{~nm}$. The apparently increased plateau value for the highest dew point can be due to slightly higher inlet pressure, increasing the aerosol flow of the instrument. The variation in the d50 due to changing dew point is less than, for example, the $0.3 \mathrm{~nm}$ reported in Kangasluoma et al. (2013) for the Airmodus A09 PSM. This is due to the smaller amount of sample flow water vapor reaching the condenser in the 3777 , since $85 \%$ of the condenser flow is dried, as compared to $0 \%$ of the condenser flow of the PSM of that time.

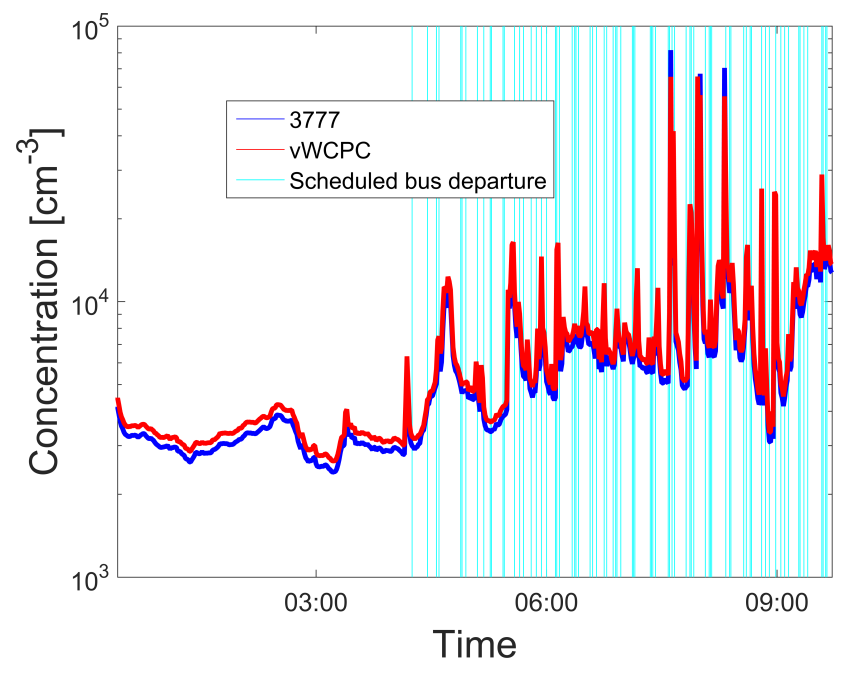

Figure 10. Concentration measured by the 3777 and vWCPC from urban atmospheric air.

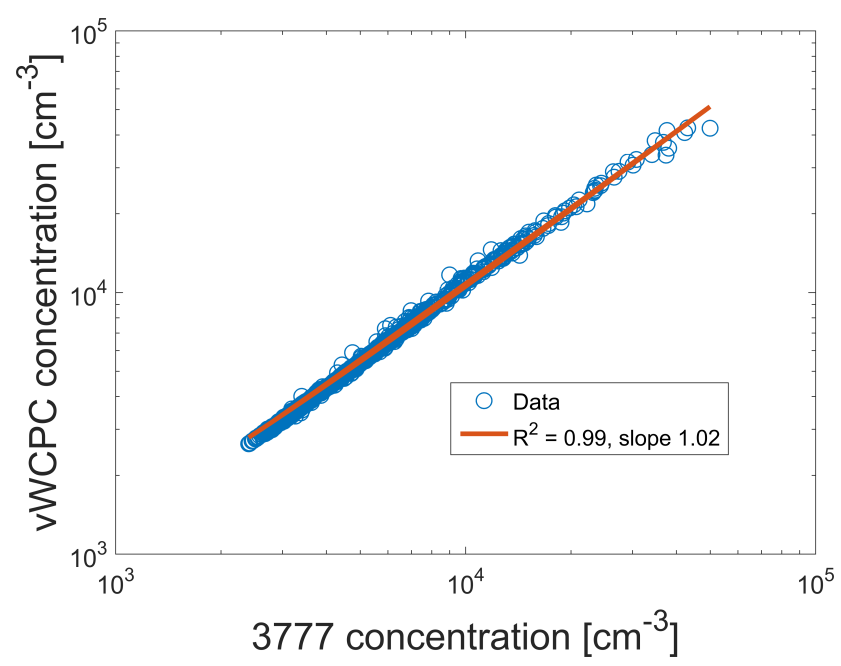

Figure 11. Correlation of the concentrations below $50000 \mathrm{~cm}^{-3}$ measured by the CPCs for the same data as in Fig. 10.

Results from the inlet flow rate experiment for the B3010 is presented in Fig. 13. The d50 curve at aerosol flow rates of $1,1.4$ and $1.6 \mathrm{~L} \mathrm{~min}^{-1}$ are rather similar within the experimental uncertainties, while at flow rate of 0.5 the detection efficiency clearly deviates to lower values at particle diameters larger than $3 \mathrm{~nm}$. This can be possibly due to larger final droplet diameters and subsequent gravitational losses at the low flow rate. A similar increase in the detection efficiency with higher flow rate as in Kangasluoma et al. (2015a) was not observed, which can be due to the differences in the saturator designs between the 3010 and 3772: 3010 has a single hole reservoir-type saturator, while 3772 has eight hole multi-tube saturator which possibly saturates the sample flow better than the one hole saturator at higher flow rates. 


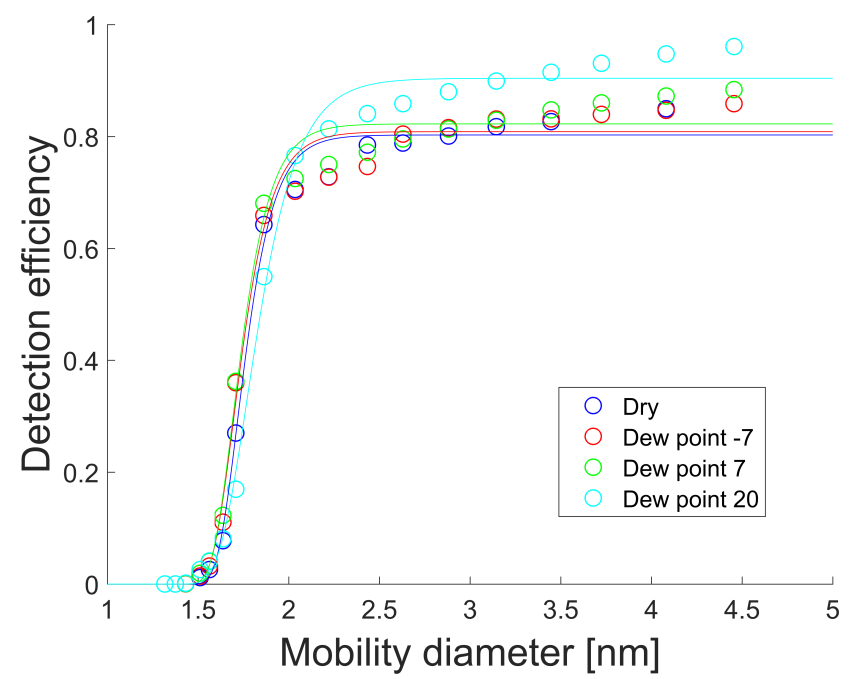

Figure 12. Detection efficiency of the 3777 as a function of the particle diameter and sample flow dew point.

As with all CPCs, the peak supersaturation, and hence the lowest detectable particle size, can be affected by the presence of other particles in the flow due to a combination of condensational heat release and vapor depletion. These effects for the original WCPCs were explored by Lewis and Hering (2013) and are evaluated here for the vWCPC. Figure 14 shows the concentration-dependent response at four particle sizes for the vWCPC. The maximum concentration at each size was determined by the maximum concentration we were able to pass through the DMA. The data are corrected for dead time, as described by Hering et al. (2005), and as is standard for most of the commercial CPCs. This approach uses the instrument dead time multiplied by a dead time correction factor, which accounts for the increase in effective dead time due to overlapping tails in pulses below the threshold. For this data set the dead time correction factor was set to 1.23 to yield a linear response to concentration at $4.4 \mathrm{~nm}$. Then this same dead time correction factor was applied to measurements at other sizes. The curves of the three smallest particle sizes have a negative slope due to the reduction in supersaturation at high concentrations caused by condensational heating (Lewis and Hering, 2013). However, the effect is relatively small, with the detection efficiency at $1.8 \mathrm{~nm}$ dropping from $36 \%$ at a concentration of $3000 \mathrm{~cm}^{-3}$ to $33 \%$ at a concentration of $90000 \mathrm{~cm}^{-3}$.

\section{Conclusions}

Three new sub-3 nm CPCs, the boosted 3010-type CPC, ADI versatile water CPC and the TSI 3777 nano enhancer, were characterized for the d50 diameter. The boosted 3010-type CPC was shown to be able to detect tungsten oxide particles smaller than $3 \mathrm{~nm}$. The vWCPC and 3777 were characterized with similar test aerosols with two different set-

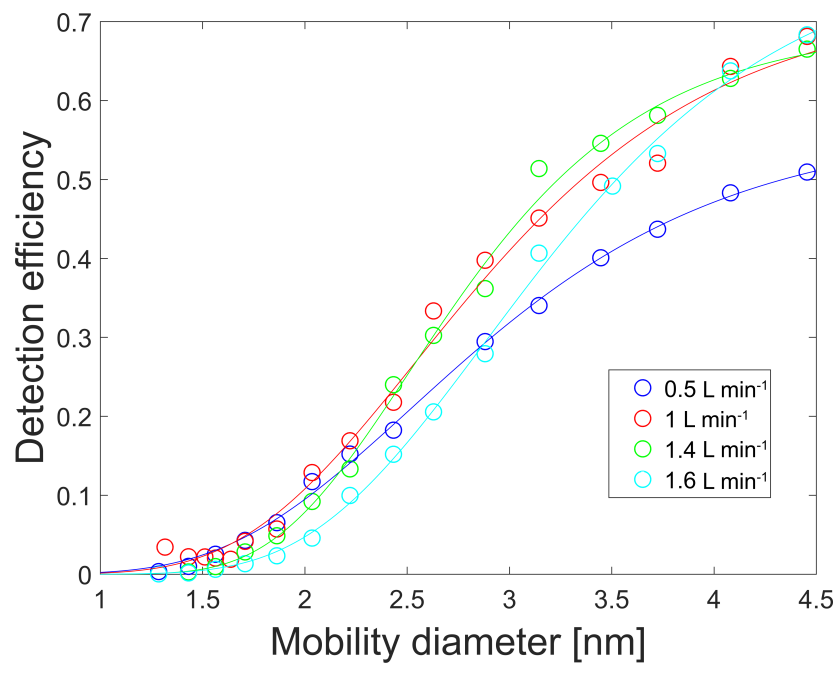

Figure 13. Detection efficiency of the B3010 as a function of the inlet flow rate.

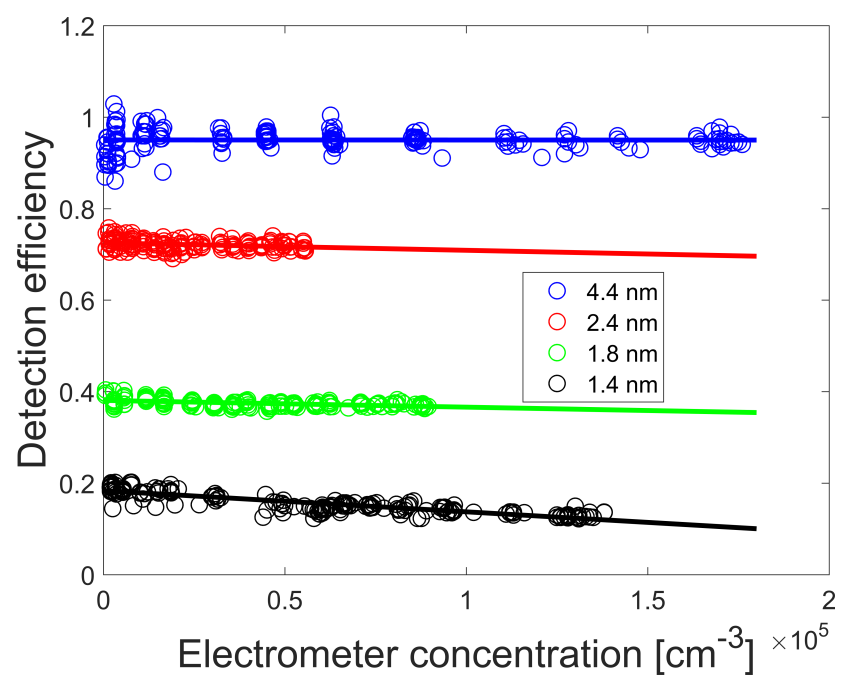

Figure 14. Ratio of the vWCPC to the electrometer as function of the particle concentration.

tings: low dT settings set so that the CPCs did not detect any ions from a radioactive charger and high dT settings set either so that the supersaturation was at the onset of homogeneous droplet formation (3777) or set to the largest value that avoids freezing or boiling (vWCPC). The $\mathrm{d} 50$ diameters for tungsten oxide were found to range from 1.7 to $2.4 \mathrm{~nm}$ at low dT and from 1.4 to $2.2 \mathrm{~nm}$ at high dT for the vWCPC. For the 3777 the d50 ranged from 1.8 to $2.3 \mathrm{~nm}$ at low dT and from 1.3 to $2.1 \mathrm{~nm}$ at high dT. Both CPCs were observed to detect charged tungsten oxide particles better than neutral ones. The organic salt particles (TDDABr) were detected less efficiently, with low dT d50 diameters of $3.3 \mathrm{~nm}$ for the vWCPC and $2.5 \mathrm{~nm}$ for the TSI-3777. When measuring the 
same atmospheric aerosol the two CPCs showed a very good agreement with regression slope of 1.02 and $R^{2}$ of 0.99 .

From the results we can make the following conclusions. The TSI 3010 hardware can be tuned to accomplish $3 \mathrm{~nm}$ particle detection by increasing the dT but not by increasing the inlet flow rate, which is in line with Buzorius (2001). This is possibly due to imperfect flow saturation in the reservoirtype saturator as opposed to the multi-hole saturator of TSI 3772 and planar-type saturator of Airmodus A20 (Kangasluoma et al., 2015a). Due to the variations in the d50 with test particle composition for the vWCPC and 3777, a careful CPC calibration should be conducted with the same particle composition as of the sampled particles. If the composition of the sampled particles is completely unknown, the obtained particle concentrations at the size range of the d50 can have significant uncertainties. The effect of particle charge on the d50 was shown to be up to approximately $0.5 \mathrm{~nm}$, which has implications for system characterizations where the fraction of charged particles can be expected to be high (Wang et al., 2017), or CPC calibration is conducted with charged particles, sampled particles are neutral and high precision d50 is required.

Data availability. Data are available from the corresponding author.

Competing interests. The laminar flow, water condensation technology presented here is covered by multiple patents assigned to Aerosol Dynamics Inc., who is the employer of two of the authors, Susanne Hering and Greg Lewis.

Acknowledgements. The authors acknowledge TSI Inc. who provided the control boards and optics for the vWCPC and who loaned the TSI 3777 for these experiments. The research was partly funded by the European Research Council (ATMNUCLE, 227463), Academy of Finland (Center of Excellence Program projects 1118615 and 139656), European Commission Seventh Framework Programme (ACTRIS2 contract no. 654109, PPP and EUROCHAMP-2020), Labex ClerVolc contribution no. 228 and Maj and Tor Nessling Foundation (grant 201700296).

Edited by: P. Herckes

Reviewed by: three anonymous referees

\section{References}

Aalto, P., Hameri, K., Becker, E., Weber, R., Salm, J., Makela, J. M., Hoell, C., O’Dowd, C. D., Karlsson, H., Hansson, H. C., Vakeva, M., Koponen, I. K., Buzorius, G., and Kulmala, M.: Physical characterization of aerosol particles during nucleation events, Tellus B, 53, 344-358, 2001.
Buzorius, G.: Cut-off sizes and time constants of the CPC TSI 3010 operating at 1-3 $\mathrm{L} \mathrm{min}^{-1}$ flow rates, Aerosol Sci. Tech., 35, 577585, 2001.

Hering, S. V. and Stolzenburg, M. R.: A method for particle size amplification by water condensation in a laminar, thermally diffusive flow, Aerosol Sci. Tech., 39, 428-436, 2005.

Hering, S. V., Stolzenburg, M. R., Quant, F. R., Oberreit, D. R., and Keady, P. B.: A laminar-flow, water-based condensation particle counter (WCPC), Aerosol Sci. Tech., 39, 659-672, 2005.

Hering, S. V., Spielman, S. R., and Lewis, G. S.: Moderated, WaterBased, Condensational Particle Growth in a Laminar Flow, Aerosol Sci. Tech., 48, 401-408, 2014.

Hering, S. V., Lewis, G. L., Spielman, S. R., Eiguren-Fernandez, A., Kreisberg, N. M., Kuang, C., and Attoui, M.: Detection near 1-nm with a Laminar-Flow, Water-Based Condensation Particle Counter, Aerosol Sci. Tech., 51, 354-362, 2016.

Iida, K., Stolzenburg, M. R., McMurry, P. H., Smith, J. N., Quant, F. R., Oberreit, D. R., Keady, P. B., Eiguren-Fernandez, A., Lewis, G. S., Kreisberg, N. M., and Hering, S. V.: An ultrafine, waterbased condensation particle counter and its evaluation under field conditions, Aerosol Sci. Tech., 42, 862-871, 2008.

Iida, K., Stolzenburg, M. R., and McMurry, P. H.: Effect of Working Fluid on Sub-2 nm Particle Detection with a Laminar Flow Ultrafine Condensation Particle Counter, Aerosol Sci. Tech., 43, 81-96, 2009.

Jiang, J. K., Chen, M. D., Kuang, C. A., Attoui, M., and McMurry, P. H.: Electrical Mobility Spectrometer Using a Diethylene Glycol Condensation Particle Counter for Measurement of Aerosol Size Distributions Down to $1 \mathrm{~nm}$, Aerosol Sci. Tech., 45, 510-521, 2011a.

Jiang, J. K., Zhao, J., Chen, M. D., Eisele, F. L., Scheckman, J., Williams, B. J., Kuang, C. A., and McMurry, P. H.: First Measurements of Neutral Atmospheric Cluster and 1-2 nm Particle Number Size Distributions During Nucleation Events, Aerosol Sci. Tech., 45, 2-5, 2011 b.

Kangasluoma, J., Junninen, H., Lehtipalo, K., Mikkilä, J., Vanhanen, J., Attoui, M., Sipilä, M., Worsnop, D., Kulmala, M., and Petäjä, T.: Remarks on Ion Generation for CPC Detection Efficiency Studies in Sub-3-nm Size Range, Aerosol Sci. Tech., 47, 556-563, 2013.

Kangasluoma, J., Kuang, C., Wimmer, D., Rissanen, M. P., Lehtipalo, K., Ehn, M., Worsnop, D. R., Wang, J., Kulmala, M., and Petäjä, T.: Sub-3 nm particle size and composition dependent response of a nano-CPC battery, Atmos. Meas. Tech., 7, 689-700, https://doi.org/10.5194/amt-7-689-2014, 2014.

Kangasluoma, J., Ahonen, L., Attoui, M., Vuollekoski, H., Kulmala, M., and Petäjä, T.: Sub-3 nm Particle Detection with Commercial TSI 3772 and Airmodus A20 Fine Condensation Particle Counters, Aerosol Sci. Tech., 49, 674-681, 2015a.

Kangasluoma, J., Attoui, M., Junninen, H., Lehtipalo, K., Samodurov, A., Korhonen, F., Sarnela, N., Schmidt-Ott, A., Worsnop, D., Kulmala, M., and Petäjä, T.: Sizing of neutral sub $3 \mathrm{~nm}$ tungsten oxide clusters using Airmodus Particle Size Magnifier, J. Aerosol Sci., 87, 53-62, 2015 b.

Kangasluoma, J., Attoui, M., Korhonen, F., Ahonen, L., Siivola, E., and Petäjä, T.: Characterization of a Herrmann type high resolution differential mobility analyzer, Aerosol Sci. Tech., 50, 222229, 2016 a. 
Kangasluoma, J., Samodurov, A., Attoui, M., Franchin, A., Junninen, H., Korhonen, F., Kurtén, T., Vehkamäki, H., Sipilä, M., Lehtipalo, K., Worsnop, D., Petäjä, T., and Kulmala, M.: Heterogeneous nucleation onto ions and neutralized ions - insights into sign-preference, J. Phys. Chem. C, 120, 7444-7450, 2016 b.

Kuang, C., Chen, M., Zhao, J., Smith, J., McMurry, P. H., and Wang, J.: Size and time-resolved growth rate measurements of 1 to $5 \mathrm{~nm}$ freshly formed atmospheric nuclei, Atmos. Chem. Phys., 12, 3573-3589, https://doi.org/10.5194/acp-12-3573-2012, 2012a.

Kuang, C., Chen, M. D., McMurry, P. H., and Wang, J.: Modification of Laminar Flow Ultrafine Condensation Particle Counters for the Enhanced Detection of $1 \mathrm{~nm}$ Condensation Nuclei, Aerosol Sci. Tech., 46, 309-315, 2012 b.

Kupc, A., Bischof, O., Tritscher, T., Beeston, M., Krinke, T., and Wagner, P. E.: Laboratory Characterization of a New NanoWater-Based CPC 3788 and Performance Comparison to an Ultrafine Butanol-Based CPC 3776, Aerosol Sci. Tech., 47, 183191, 2013

Lewis, G. S. and Hering, S. V.: Minimizing Concentration Effects in Water-Based, Laminar-Flow Condensation Particle Counters, Aerosol Sci. Tech., 47, 645-654, 2013.

Mertes, S., Schroder, F., and Wiedensohler, A.: The ParticleDetection Efficiency Curve of the Tsi-3010 Cpc as a Function of the Temperature Difference between Saturator and Condenser, Aerosol Sci. Tech., 23, 257-261, 1995.

Okuyama, K., Kousaka, Y., and Motouchi, T.: Condensational Growth of Ultrafine Aerosol-Particles in a New Particle-Size Magnifier, Aerosol Sci. Tech., 3, 353-366, 1984.

Peineke, C., Attoui, M. B., and Schmidt-Ott, A.: Using a glowing wire generator for production of charged, uniformly sized nanoparticles at high concentrations, J. Aerosol Sci., 37, 16511661, 2006.

Russell, L. M., Zhang, S. H., Flagan, R. C., Seinfeld, J. H., Stolzenburg, M. R., and Caldow, R.: Radially classified aerosol detector for aircraft-based submicron aerosol measurements, J. Atmos. Ocean. Technol., 13, 598-609, 1996.

Seto, T., Okuyama, K., de Juan, L., and Fernández de la Mora, J.: Condensation of supersaturated vapors on monovalent and divalent ions on varying size, J. Chem. Phys., 107, 1576-1585, 1997.

Sipilä, M., Lehtipalo, K., Attoui, M., Neitola, K., Petäjä, T., Aalto, P. P., O'Dowd, C. D., and Kulmala, M.: Laboratory Verification of PH-CPC's Ability to Monitor Atmospheric Sub-3 nm Clusters, Aerosol Sci. Tech., 43, 126-135, 2009.
Stolzenburg, M. R. and McMurry, P. H.: An Ultrafine Aerosol Condensation Nucleus Counter, Aerosol Sci. Tech., 14, 48-65, 1991.

Ude, S. and Fernández de la Mora, J.: Molecular monodisperse mobility and mass standards from electrosprays of tetra-alkyl ammonium halides, J. Aerosol Sci., 36, 1224-1237, 2005.

Vanhanen, J., Mikkilä, J., Lehtipalo, K., Sipilä, M., Manninen, H. E., Siivola, E., Petäjä, T., and Kulmala, M.: Particle Size Magnifier for Nano-CN Detection, Aerosol Sci. Tech., 45, 533-542, 2011.

Wang, Y., Kangasluoma, J., Attoui, M., Fang, J., Junninen, H., Kulmala, M., Petäjä, T., and Biswas, P.: The high charge fraction of flame-generated particles in the size range below $3 \mathrm{~nm}$ measured by enhanced particle detectors, Combust Flame, 176, 72 80, 2017.

Weber, R. J., Marti, J. J., McMurry, P. H., Eisele, F. L., Tanner, D. J., and Jefferson, A.: Measured atmospheric new particle formation rates: Implications for nucleation mechanisms, Chem. Eng. Commun., 151, 53-64, 1996.

Wiedensohler, A., Orsini, D., Covert, D. S., Coffmann, D., Cantrell, W., Havlicek, M., Brechtel, F. J., Russell, L. M., Weber, R. J., Gras, J., Hudson, J. G., and Litchy, M.: Intercomparison study of the size-dependent counting efficiency of 26 condensation particle counters, Aerosol Sci. Tech., 27, 224-242, 1997.

Wilson, J. C., Blackshear, E. D., and Hyun, J. H.: An Improved Continuous-Flow Condensation Nucleus Counter for Use in the Stratosphere, J. Aerosol Sci., 14, 387-391, 1983.

Wimmer, D., Lehtipalo, K., Franchin, A., Kangasluoma, J., Kreissl, F., Kürten, A., Kupc, A., Metzger, A., Mikkilä, J., Petäjä, T., Riccobono, F., Vanhanen, J., Kulmala, M., and Curtius, J.: Performance of diethylene glycol-based particle counters in the sub-3 nm size range, Atmos. Meas. Tech., 6, 1793-1804, https://doi.org/10.5194/amt-6-1793-2013, 2013.

Winkler, P. M., Steiner, G., Vrtala, A., Vehkamäki, H., Noppel, M., Lehtinen, K. E. J., Reischl, G. P., Wagner, P. E., and Kulmala, M.: Heterogeneous nucleation experiments bridging the scale from molecular ion clusters to nanoparticles, Science, 319 , 1374-1377, 2008. 